\section{A giant gastric bezoar in Billroth II stomach: a case report on successful endoscopic removal via repeated fragmentation and dissolution technique negating the need for surgical intervention}

\author{
Jin Yu Chieng, ${ }^{1}$ Shiaw Hooi Ho, ${ }^{2}$ \\ Khean Lee Goh² \\ ${ }^{1}$ Department of Medicine, Faculty \\ of Medicine and Health Science, Putra \\ University of Malaysia, Selangor; \\ 2Department of Medicine, University \\ of Malaya, Kuala Lumpur, Malaysia
}

\section{Abstract}

A 76-year-old gentleman presented with anemia. He had a history of perforated duodenal ulcer six years ago, with Billroth II repair performed. A large gastric bezoar $\left(8 \times 6 \mathrm{~cm}^{2}\right)$ with a clean base ulcer at the anastomotic junction was found during the initial oesophago-gastro-duodenoscopy (OGDS). Rapid urease test was negative. He presented with melena during the subsequent follow up (OGDS showed a Forrest Ib prepylori ulcer). We have successfully removed the gastric bezoar with dissolution therapy initially (injection of cokecola into the bezoar, followed by drinking 325 $\mathrm{mL}$ Coca-Cola ${ }^{\mathrm{TM}}$ twice daily), followed by four attempts of OGDS with endoscopic fragmentation. Histopathology reported as degenerated vegetable matter, acellular debris mixed with scattered fungal and bacterial colonies, which was compatible with bezoar. Follow-up OGDS showed complete clearance of the bezoar. Coca-Cola ${ }^{\mathrm{TM}}$ ingestion should be considered as initial treatment as it is non-invasive, and it enables further successful endoscopic fragmentation.

\section{Introduction}

A bezoar is an indigestible mass of material, such as hair, food, seeds, that other ingested substances found in the gastrointestinal tract. ${ }^{1}$ Gastric bezoars are rare with estimated incidence about $0.4 \%$ on upper endoscopy. ${ }^{2}$

Gastric bezoars usually result from ingestion of indigestible material in patients with impairment in the gastric motility or digestion, which could be due to previous gastric surgery (such as Billroth I or II gastrectomy) or in the patients with delaying gastric emptying (such as those with diabetic gastroparesis, mixed connective tissue disease, or hypothyroidism. ${ }^{2-}$ ${ }^{4}$ Other predisposing conditions are inadequate fluid intake leading to dehydration, and anatomic abnormalities such as diverticula or gastric outlet obstruction., ${ }^{1,2}$

Most of the patients are fairly asymptomatic initially. Abdominal pain (70\%), nausea and vomiting (64\%), and early satiety are the main clinical symptoms. 1,2,4,5 Gastric bezoars may result in peptic ulcer disease from pressure necrosis ${ }^{6}$ and subsequent gastrointestinal bleeding as well as gastric outlet obstruction. ${ }^{7,8}$

A wide variety of therapeutic options have been reported. Medical treatment includes dissolution with ingestion of cellulose, papain, or $\mathrm{N}$-acetylcysteine. ${ }^{1,2,5,9-13}$ Ingestion of carbonated beverage Coca-Cola has been successfully used to dissolve bezoars. ${ }^{4,14-16}$ Endoscopic management includes mechanical fragmentation of the bezoar using water jet with subsequent extraction, a drill device, tripod forceps, polypectomy snare plus diathermy, mechanical lithotripter, or Dormia basket. ${ }^{2,3,17}$ Surgical intervention would be indicated if endoscopic removal fails.

We report a male patient with a history of gastric surgery presented with peptic ulcer disease secondary to a giant gastric bezoar.

\section{Case Report}

A 76-year-old gentleman was referred from Healthcare Clinic for iron deficiency anemia with positive fecal occult blood test. The patient had a history of perforated duodenal ulcer six years ago, with laparotomy repair (Billroth II) performed. He had mild epigastric discomfort. His bowel habits had never changed. He did not report any loss of weight or appetite. He denied of taking any traditional or herbal medicine, nor the analgesic or steroid abuse. He denied of smoking. He did not have any history of malaenic stool or hematemesis initially. He was clinically mild pallor. Laboratory data showed iron deficiency anemia (hemoglobin level $9.1 \mathrm{~g} / \mathrm{L}$ with low mean cell volume and low mean cell hemoglobin, together with low serum iron, ferritin and transferrin saturation level).

A large gastric bezoar (about $8 \times 6 \mathrm{~cm}^{2}$, of hard consistency) with an anastomotic junction ulcer (Forrest class III, with clean base) was diagnosed during the oesophago-gastroduodenoscopy (OGDS) (Figure 1). Rapid urease test was negative. Biopsies of the ulcer were taken, and reported as chronic active gastritis with intestinal metaplasia histopathologically. At the time of diagnosis, no attempt was made to remove or mechanically disrupt the bezoar. Proton pump inhibitor was prescribed
Correspondence: Jin Yu Chieng, Department of Medicine, Faculty of Medicine and Health Science, Putra University of Malaysia, 43400 Serdang UPM, Selangor, Malaysia

Tel.: +60.006.016.8580155.

E-mail: cjy511@yahoo.com

Key words: Anemia; Bezoar; Oesophago-gastroduodenoscopy; OGDS; Ulcer.

Contributions: the authors contribute equally.

Conflict of interest: the authors declare no potential conflict of interest.

Received for publication: 29 July 2016 . Accepted for publication: 12 August 2016.

This work is licensed under a Creative Commons Attribution NonCommercial 4.0 License (CC BYNC 4.0).

(C) Copyright J. Yu Chieng et al., 2016

Licensee PAGEPress, Italy

Gastroenterology Insights 2016; 7:6808

doi:10.4081/gi.2016.6808

as outpatient.

During the first OGDS attempt, we found that the bezoar was too hard to be segmented by using biopsy forcep/baskets/polypectomy snare/tripod forceps/Argon plasma coagulation alone. Only superficial pieces were removed.

After review the literature, decision had been made to try to remove the gastric bezoar by endoscopic fragmentation techniques and dissolution therapy. In total, 5 sections of OGDSs had been performed to remove the bezoar under sedation (intravenous midazolam/fentanyl).

During the second OGDS attempt, we injected, via variceal needle, inside the bezoar 200 $\mathrm{mL}$ of Coca-Cola. The patient was instructed to drink at least one $325 \mathrm{ml}$ can of Coca-Cola twice daily.

During the third review, the patient claimed he had passing out malaenic stool. Hemoglobin level was $9.2 \mathrm{~g} / \mathrm{dL}$. OGDS reviewed a bleeding anastomotic junction ulcer (Forrest class Ib), with the gastric bezoar. The bleeding had been successful secured by combination of adrenaline injection and heater probe application. He was warded for blood transfusion together with infusion proton pump inhibitor. He was discharged well three days later.

During the subsequent OGDSs, the anastomotic junction ulcer was found to be healed. We noticed that the bezoar had become much softer, and easier to be segmented into small pieces by using hot polypectomy snare. The bezoar had been completely removed by using a therapeutic scope with a roth net during the fourth OGDS attempt (Figure 2). 
Histopathology reported as mainly degenerated vegetable matter, acellular debris mixed with scattered fungal and bacterial colonies, which was compatible with bezoar.

Follow-up OGDS showed complete clearance of the bezoar (Figure 3). Subsequent hemoglobin levels were stable then.

The interval of time from the initiation of treatment to endoscopic confirmation of bezoar clearance was 12 weeks.

\section{Discussion}

This patient had previous history of Billroth II surgery, which was a factor for formation of gastric bezoar. He presented to us with iron deficiency anemia, and the diagnostic OGDS shown peptic ulcer disease, which developed bleeding later on. This could be due to pressure ulcer as the Rapid urease test was negative.

Lee and colleagues had published a series with 17 patients, which shown combination treatment with dissolution therapy and endoscopic fragmentation technique were able to dissolve nearly all bezoars (16/17), while dissolution therapy alone was successful in only $25 \%$ of the cases. ${ }^{18}$ In our case, we successes to soften the gastric bezoar by ingestion of Coca-Cola, and to segment the bezoar into smaller pieces using hot polypectomy snare, followed by removal with roth net.

Coca-Cola ingestion is a cheap, easy-to-perform and safe procedure that can be accomplished at any endoscopy unit. The mechanism of bezoar dissolution by Coca-Cola has not been thoroughly explained. It is believed that the sodium bicarbonate in Coca-Cola has a mucolytic effect, and the carbon dioxide bubbles may penetrate into the bezoar, leading to digestion of the fibers. Coca-Cola's low $\mathrm{pH}$ level (close to normal gastric secretions' $\mathrm{pH}$ level) is important for the digestion of the fiber by acidifying the gastric content. Coca-Cola diminishes the size and softens the hard consistency of the bezoar, thus facilitating the dissolution by hot polypectomy snare.

\section{Conclusions}

This study shows a successful removal of a large gastric bezoar with dissolution therapy using Coca-cola, followed by endoscopic fragmentation techniques. Coca-cola ingestion should be considered as initial treatment as it is non-invasive, and it enables further successful endoscopic fragmentation.
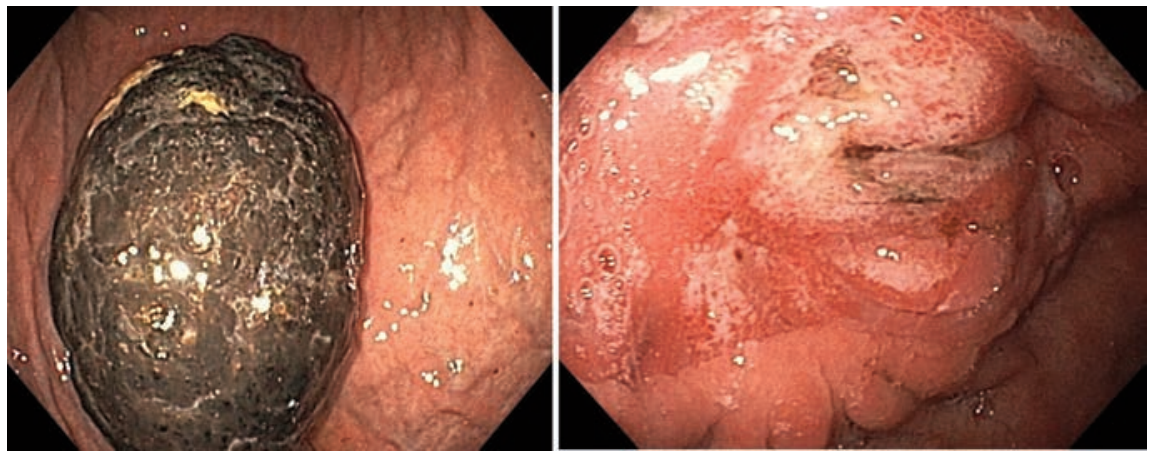

Figure 1. An endoscopic view of the gastric bezoar in the patient, with a prepyloric ulcer (Forrest class III with clean base).

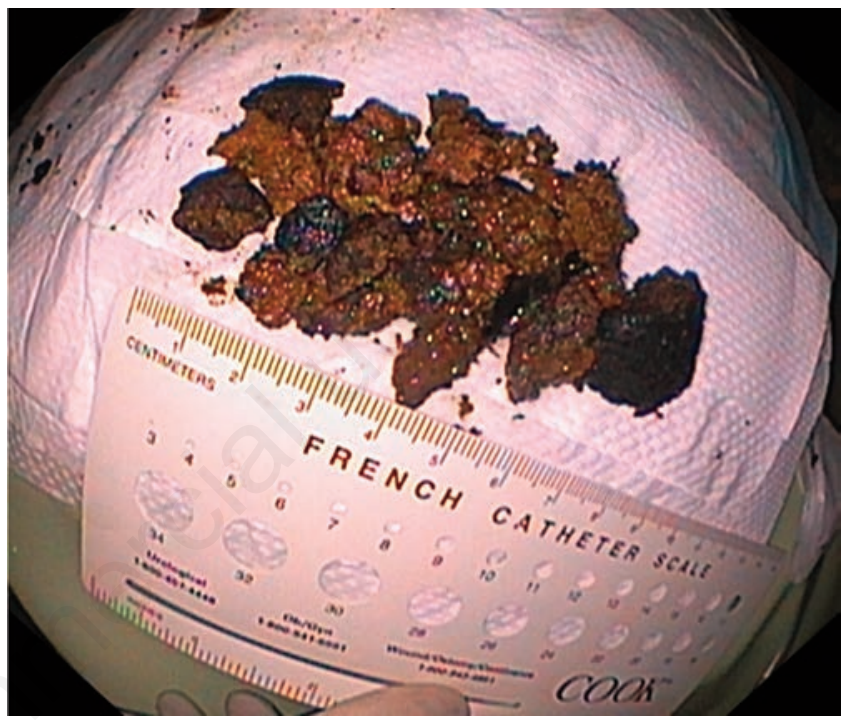

Figure 2. The fragments of the gastric bezoar removed from the stomach.

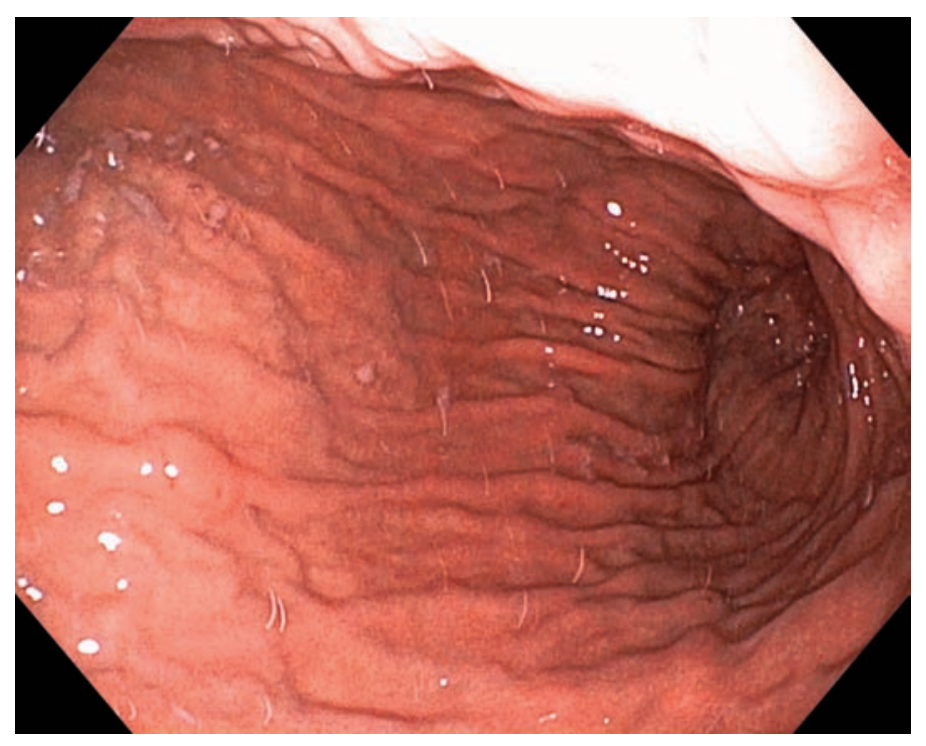

Figure 3. After treatment, there was complete resolution of the gastric bezoar. 


\section{References}

1. Walker-Renald P. Update on the medicinal management of phytobezoars. Am J Gastroenterol 1993;88:1663-6.

2. Andrus CH, Ponsky JL. Bezoars: classification, pathophysiology and treatment. Am J Gastroenterol 1988;83:476-8.

3. Lee J. Bezoars and foreign bodies of the stomach. Gastrointest Endosc Clin N Am 1996;6:605-19.

4. Ladas SD, Triantafyllou K, Tzathas C, et al. Gastric phytobezoars may be treated by nasogastric coca-cola lavage. Eur J Gastroenterol Hepatol 2002;14:801-3.

5. Rider JA, Foresti-Lorente RF, Garrido J, et al. Gastric bezoars: treatment and prevention. Am J Gastroenterol 1984;79:357-9.

6. DeBakey M, Oshner A. Bezoars and concretions. Surgery 1938;4:934.

7. Lo CY, Lau PW. Small bowel phytobezoar: an uncommon cause of small bowel obstruction. Aust N Z J Surg 1994;64:1879.

8. Leung E, Barnes R, Wong L. Bezoar in gastro-jejunostomy presenting with symptoms of gastric outlet obstruction: a case report and review of the literature. J Med Case Rep 2008;2:323

9. Pollard HB, Block GE. Rapid dissolution of phytobezoar by cellulase enzyme. Am J Surg 1968;116:933-6.

10. Smith BH, Mollot M, Berk JE. Use of cellulase for phytobezoar dissolution. Am J Gastroenterol 1980;73:257-9.

11. Morato F, Sanchez I, Casseras B, Mateu de Antonio J. Cellulase treatment in 3 cases of large phytobezoars. Farm Hosp 2009;33:100-3.

12. Silva F, Goncalves C, Vasconcelos H, Cotrim I. Endoscopic and enzymatic treatment of gastric bezoars with acetylcysteine. Endoscopy 2002;34:845.

13. Bater E, Bater W, Cloney D. Resolution of a phytobezoar with Adolph's meat tenderiz- er. Pharmacotherapy 2007;27:299-302.

14. Kato H, Nakamura M, Orito E, et al. The first report of successful nasogastric cocacola lavage treatment for bitter persimmon phytobezoars in Japan. Am J Gastroenterol 2003;98:1662-3.

15. Chung YW, Han DS, Park YK, et al. Huge gastric diospyrobezoars successfully treated by oral intake and endoscopic injection of coca-cola. Dig Liver Dis 2006;38:515-7.

16. Harikumar R, Kunnel P, Sunilraj R. Dissolution of pharmacobezoar using carbonated beverage. Indian J Gastroenterol 2008;27:245-6.

17. Kuo J, Mo L, Tsai C, et al. Endoscopic fragmentation of gastric phytobezoar by electrohydraulic lithotripsy. Gastrointest Endosc 1993;39:706-8.

18. Beom Jae Lee, Jong-Jae Park, Hoon Jai Chun, et al. How good is cola for dissolution of gastric phytobezoars? World J Gastroenterol 2009;15:2265-9. 